\title{
Economic efficiency of application of innovative materials and structures in high-rise construction
}

\author{
Roman Golov ${ }^{1, *}$, Varvara Dikareva ${ }^{2}$, Roman Gorshkov ${ }^{2}$, Anatoly Agarkov ${ }^{3}$ \\ ${ }^{1}$ Moscow Aviation Institute (National Research University), Volokolamskoe highway, 4, Moscow, \\ 125993, Russia \\ ${ }^{2}$ Moscow State University of Civil Engineering, Yaroslavskoye sh., 26, 129337 Moscow, Russia \\ ${ }^{3}$ Moscow Financial and Economic Institute, Novomoskovskaya street, 15a, Moscow, 129075, Russia
}

\begin{abstract}
The article is devoted to the analysis of technical and economic efficiency of application of tube confined concrete structures in high-rise construction. The study of comparative costs of materials with the use of different supporting columns was carried out. The main design, operational, technological and economic advantages of the tube confined concrete technology were evaluated, conclusions were drawn about the high strength and deformation properties of axial compression of steel tubes filled with high-strength concrete. The efficiency of the tube confined concrete use is substantiated, which depends mainly on the scale factor and percentage of reinforcement affecting its load-bearing capacity.
\end{abstract}

\section{Introduction}

The key objective of high-rise construction is to reduce the weight of buildings, their material consumption, reduce the volume of building structures and labor costs. The most suitable system for such buildings is a frame or frame-core structure. In this system, bending moments arising from horizontal loads are accepted primarily by monolithic trunks or stiffening cores. The objectives, that are set by traditional methods and materials, cannot be solved. The questions of creating effective designs of high reliability and minimum weight are posed.

These requirements are met by building structures from tube confined concrete. Tube confined concrete is a complex structure, consisting of a steel shell and a concrete core, working together. Tube confined concrete elements, that perform little flexibility and small eccentricities of longitudinal force application (which is typical for vertical load-bearing elements of high-rise building frames), have an exceptionally high load-bearing capacity at relatively small cross sections, being an example of a successful combination of valuable properties of metal and concrete. This gives significant savings in steel and concrete, leads to a reduction in the cross-sectional dimensions of the elements, their mass and transport

\footnotetext{
${ }^{*}$ Corresponding author: roman_golov@,rambler.ru
} 
costs, as well as the preservation of all the advantages of metal structures in terms of installation.

This is facilitated by the confinement effect, which creates a steel shell for the concrete core, performing simultaneously the functions of both longitudinal and transverse reinforcement. This effect is especially manifested in columns of circular cross section. The lateral pressure of the pipe prevents the intensive development of microcracks in the fracture in the concrete core, which, under conditions of comprehensive crimping, withstands stresses that greatly exceed the prismatic strength. The steel casing, in turn, is protected from loss of local and general stability due to the favorable effect of the internal pressure of the solid medium.

\section{Materials and Methods}

The main point in the construction of high-rise buildings, taking into account the use of tube confined concrete elements, is to ensure the joint work of the concrete core and the steel shell under operational loads, which is an essential design drawback of these structures. In terms of the difference in the initial coefficients of transverse deformation of concrete and steel $(\mathrm{vb} \approx 0.18, \mathrm{vs} \approx 0.3)$, during the gradual loading, the core and the casing work jointly only in the initial loading period. Then, the outer shell tends to tear away from the surface of the concrete, because of the indicated difference in deformation properties and low strength of the bonding of concrete to steel, contributing to the occurrence of radial tensile stresses in it, which leads to a disbonding. At this moment, there is no natural transverse compression of concrete in the tube, and concrete works under uniaxial compression conditions, whereas the tube - as a longitudinal reinforcement. Due to this drawback, the issue of modeling the tube confined concrete element in simple computing systems (Scad, Lira, etc.), which takes into account the properties of the materials in the complex, has not been resolved.

When constructing high-rise buildings with tube confined concrete structures, it is necessary to take into account the structure of butt joints of columns in height and overlap, which requires additional study of the main structural interfaces to other constructions of the building and the development of fundamentally new structural and technological solutions. An industrial and high-performance method is required to fill the tubes with concrete, which ensures high strength and uniformity of the concrete core, when using tube confined concrete structures

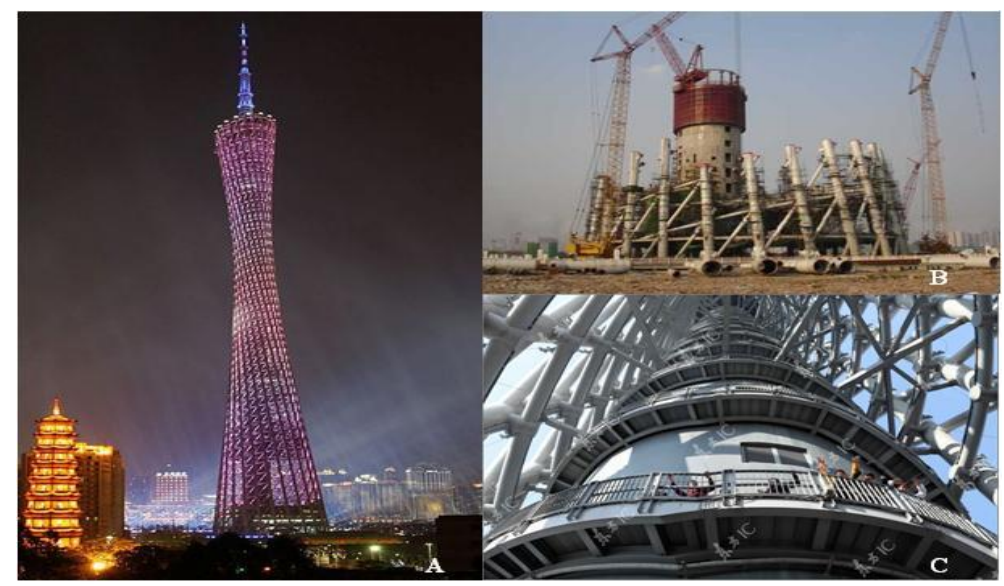

Fig. 1. The "Canton Tower" TV Tower with the height of $600 \mathrm{~m}$ (Guangzhou). a - the general view of the tower; $\mathrm{b}$ - course of construction, $\mathrm{c}$ - shell of tube confined concrete elements. 
In 2010, one of the world's tallest structures was built in Guangzhou. This is the $600 \mathrm{~m}$ TV tower "Canton Tower" (Figure 1), which has a unique architectural cone-shape.

The monolithic reinforced concrete trunk is closed by a shell of a triangular lattice consisting of tube confined concrete elements. This design allows wind flows to pass through the structure without creating swirls, which guarantees the stability of the tower during the typhoons [1]. The new constructional system "SWMB", named after the company that developed it, "Skilling Word Magnusson Berkshire Inc." in the 1970s, contributed to the construction of even more than a dozen high-rise buildings in the US that demonstrated the efficiency of tube confined concrete. A special feature of the system is the use of tube confined concrete structures as columns of ultra-high-strength concrete [2].

Specialists also note that the use of tube confined concrete columns with high-strength concrete provides seismic stability of the skyscrapers. Low material intensity, high fire resistance of tube confined concrete, the possibility of combination with various structures of overlapping is noted by French specialists who develop frame-type structural systems of buildings with supporting columns of tube confined concrete.

\section{Results}

The efficiency of these or other building structures is determined by the consumption of necessary for their production materials, labor efforts and, finally, the cost of these structures. As experience of design construction of structures from tube confined concrete shows, saving of materials, labor and cost is achieved, when using tube confined concrete. For example, in comparison with a metal span structure, the actual cost of a tube confined concrete bridge, which was built by V.A. Rosnovsky, turned out to be $20 \%$ less. At the same time, savings of metal amounted to $52 \%$. When replacing reinforced concrete columns with tube confined concrete ones at the Semiluki plant, the expenses were almost halved. In addition, the tube confined concrete pillar weighs only about 2 tons comparing with a design weight of a reinforced concrete column of more than 13 tons. A great reduction in the cost of structures has been achieved. High economic efficiency of tube confined concrete structures has been proved in various works long time ago. An important advantage of tube confined concrete structures in comparison with regular reinforced concrete is that they do not need any embedded parts and formwork, since the casing and the fittings are replaced by a casing tube. Many embedded parts of various purposes and types are used in reinforced concrete columns. Today, there is a huge number of standard sizes of embedded parts, which does not allow to ensure the rhythm of their configuration. According to our research, tube confined concrete has an exceptionally high load-bearing capacity with small cross sections of columns, being an excellent example of the optimal combination of outstanding metal and concrete capabilities (Table 1). At the same time, steel tubes act as a fixed formwork when concreting, providing both longitudinal and transverse reinforcement of concrete. It takes loads in all directions and at any angle. Concrete in the tube confined concrete structures is under conditions of all-round compression and it withstands stress, which substantially exceeds its prismatic strength [3].

Experience in the construction of buildings with tube confined concrete structures showed the advantages of using such structures, which is confirmed by numerous studies in different countries. It is possible to compare the technical and economic efficiency of tube confined concrete structures with steel and reinforced concrete structures using the example of designed industrial and civil structures. The economics and expediency of the tube confined concrete structures of the skelp mill-300 of the Krivoy Rog metallurgical plant is reflected by the data: direct costs for building structures are decreased by $40 \%$, labor effort - by $38 \%$. 
Table 1. Comparative costs of materials on supporting columns (1500 tons load)

\begin{tabular}{|l|l|l|l|l|l|l|}
\hline $\begin{array}{l}\text { Column } \\
\text { material }\end{array}$ & $\begin{array}{l}\text { Cross- } \\
\text { sectional } \\
\text { area of the } \\
\text { column, } \mathrm{m}^{2}\end{array}$ & $\begin{array}{l}\text { Column } \\
\text { diameter, } \mathrm{m}\end{array}$ & $\begin{array}{l}\text { Area of } \\
\text { metal, } \mathrm{m}^{2}\end{array}$ & $\begin{array}{l}\text { Area of } \\
\text { concrete, } \\
\mathrm{m}^{2}\end{array}$ & $\begin{array}{l}\text { Metal } \\
\text { consumptio } \\
\mathrm{n}, \%\end{array}$ & $\begin{array}{l}\text { Concrete } \\
\text { consumption, } \\
\%\end{array}$ \\
\hline $\begin{array}{l}\text { Reinforced } \\
\text { concrete }\end{array}$ & 0.405 & 0.670 & 0.023 & 0.382 & 127 & 118 \\
\hline Metal & 0.059 & 1.000 & 0.059 & - & 304 & - \\
\hline $\begin{array}{l}\text { Tube } \\
\text { confined } \\
\text { concrete }\end{array}$ & 0.321 & 0.630 & 0.019 & 0.302 & 100 & 100 \\
\hline
\end{tabular}

The main advantages of tube confined concrete technology:

1. Structural and operational

- High load-bearing capacity of tube confined concrete columns

- Efficiency of the steel casing - tubes instead of fittings

- Increase of strength and durability parameters of concrete in the tube

- Three-axial compression of concrete in the tube

- Reduction of the weight of the structural frame of the building

- Increase of fire resistance of steel frame structures

- High building resistance to seismic effects, explosions, extreme loads and impacts

2. Technological

- Steel tube execution of the role of the primary frame of the building and fixed formwork for concrete

- Durability during the winter season

- High speed of erection of frames out of tube confined concrete, what is 3-4 times superior to that of classic reinforced concrete

- Reduction of welding works is 2-3 times

3. Economic

- Reduction of the consumption of metal for the erection of the building frames is $1,8-2$ times

- Reduction of the construction time of cases is 1.5-2 times

- Reduction of the cost of cases by $25-30 \%$

Parameters for metal and reinforced concrete columns were taken from the projects of the constructed facilities. Tube confined concrete columns were calculated from the loads affecting the similar steel and reinforced concrete columns. These costs include installation, painting, capital investments in related construction industries, capital investments in fixed assets, as well as operating costs. Joints are simplified in tube confined concrete columns and metal consumption is reduced. The structures of the cantilevers of the tube confined concrete columns are welded and can be solved in different ways taking into account the architectural and construction requirements. The manufacture of the column is feasible both in the conditions of factories and in the conditions of the construction site. Analysis shows that tube confined concrete elements are more efficient than reinforced concrete and steel structures. When replacing reinforced concrete structures with tube confined concrete, the consumption of concrete and metal is significantly reduced due to embedded parts, and labor costs are almost halved. The weight of the structures decreases. The use of tube confined concrete structures is particularly efficient at high loads in centrally compressed and eccentrically compressed elements with small eccentricities. Moreover, the use of tube confined concrete definitely requires additional study of the main interfaces with other structures [4].

The choice of constructional solutions during the design stage should be carried out in conjunction with the methods of manufacturing and erection adopted in the project, as well as the requirements for the economic operation of structures [5]. 
Tube confined concrete structures should be designed primarily welded, with a wide application of automatic and semi-automatic welding. Welded joints of tube confined concrete structures should be designed so that they can be carried out by simple means with the obligatory satisfaction of the requirements for quality control in the conditions of construction. The sizes of tube confined concrete structures should be assigned with account of the requirements of standardization, modularity and unification. It is necessary that the number of diameters and wall thicknesses used in one design should be kept to a minimum. Separate structural elements should be enlarged as much as the lifting capacity of the assembly mechanisms, dimensions, as well as the conditions for manufacturing and transportation allow. When designing buildings and structures with load-bearing tube confined concrete structures, clear structural schemes must be adopted to ensure the necessary strength, overall stability, and also the spatial constancy of the building or structure. Strength and stability of tube confined concrete structures should be provided both in operating conditions, and during transportation and installation. The necessary strength, rigidity and stability of tube confined concrete structures, as well as individual elements and connections at all stages of operation and erection are determined by calculation; while the design schemes must meet the accepted constructional ones. Special attention should be paid to the strength, stiffness and durability of the joints of the elements (Fig. 2) when designing the tube confined concrete building structures, ensuring reliable transfer of forces. The constructional solutions of the joints can have different variants. Pairings of tube confined concrete elements are made by means of a figured cut, which is welded along the contour without any additional fasteners.
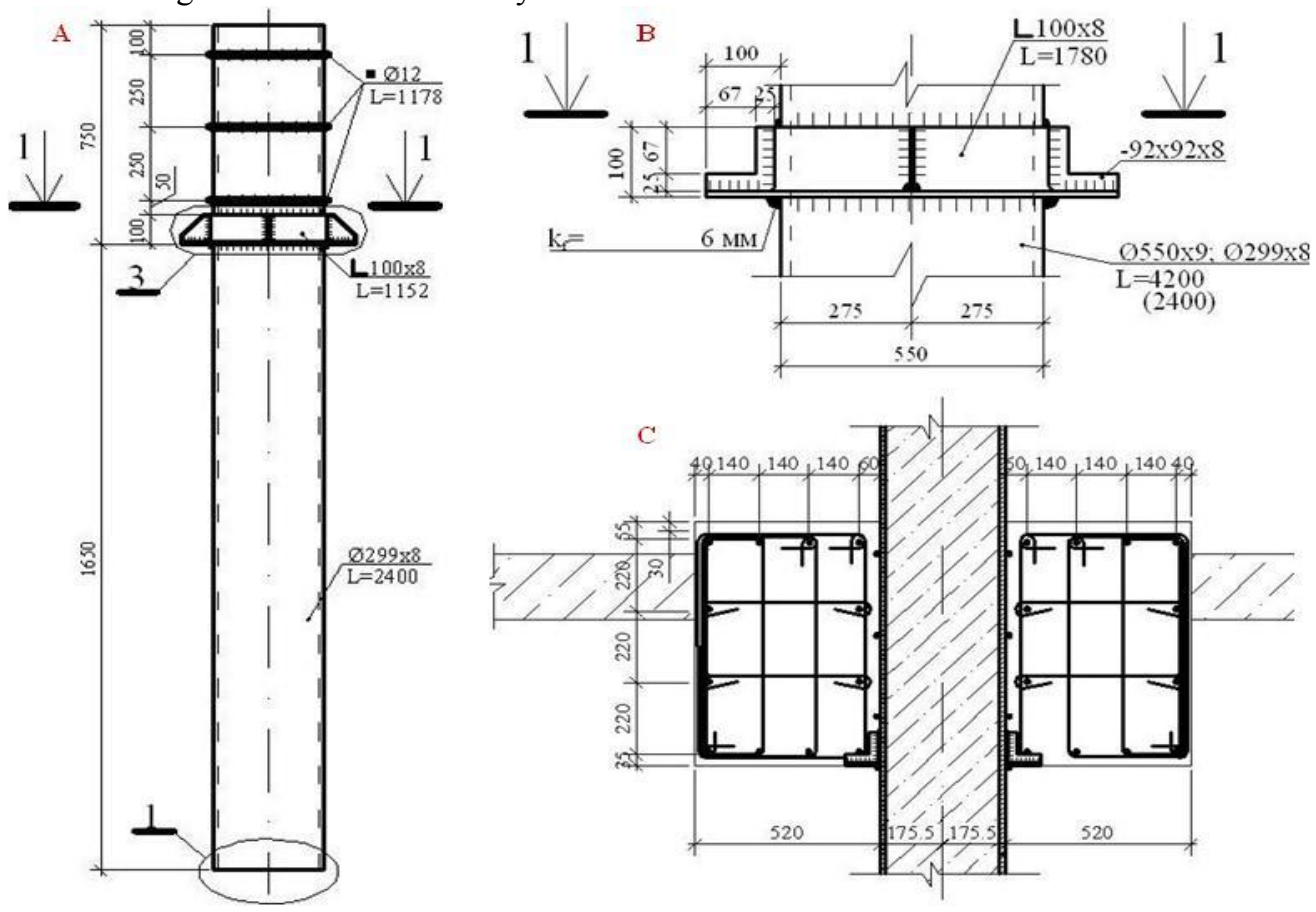

Fig. 2. A - General view of tube confined concrete columns B - Joints in general view C - Cut of tube confined concrete through section

The processing of the tube ends in this case is carried out on automatic universal installations for figured cutting of tubes. When designing tube confined concrete structures, there should be provided measures to protect them from corrosion. They should provide extra thorough coloring or protection with other coatings. Sinuses and troughs should be 
avoided at the design stage, which hinder moisture or airing. It is necessary that all parts of tube confined concrete structures are accessible for observation, cleaning and painting during operation of the facility [6].

\section{Discussions}

In the architectural and construction business, tube confined concrete structures have been being used for more than 50 years. In the Soviet Union, Europe, the United States, Japan and other industrialized countries, serious attention was paid to tube confined concrete structures 80 years ago and they were used in industrial, urban multistorey housing and high-rise buildings, multi-trestle road junctions and various special facilities.

The wide application of tube confined building structures in Russia is hindered by the absence of domestic regulatory documents for their calculation and design, not only for seismic regions, but also for non-seismic regions. Although the strength of tube confined concrete has been studied by many researchers for dozens of years. The existing methods of calculation differ significantly from each other. They do or do not take into account the material properties not in a complex, the main features and specificity of the resistance of tube confined concrete to deformation are incompletely reflected depending on the nature of the affecting load. In addition, the prospect of using high-strength concretes in tube confined concrete columns opens up, which will also make it possible to significantly reduce the cross-sectional dimensions of load-bearing structures, and hence the overall construction costs.

\section{Conclusion}

Tube confined concrete structures create conditions that reduce the phenomenon of progressive collapse due to man-caused and other impacts. As it is known, the destruction of buildings and structures can occur because of a strong earthquake. And, of course, not only from horizontal seismic forces, as it was believed up to now, but also from gravitational forces. This is the weight of the structure and the vertical component of the earthquake, affecting structures that already have seismic damages and horizontal displacements. Therefore, the advantage of tube confined concrete columns is their ability to withstand seismic impacts in the horizontal and vertical directions without being destroyed. Tube confined concrete structures are very reliable in operation. In the limiting state, they do not lose their load-bearing capacity instantly, as reinforced concrete, and for a long time are able to withstand the load, even getting large deformations, the tube confined concrete rod is able to keep carrying a significant load further on.

\section{References}

1. V.P. Kamskov,, I.V.Balandina, D.Y.Zemlyanushnov, Sovremennye tendentsii razvitiya nauki i tekhnologiy, 9-3, 95-99 (2015)

2. A.N. Grishina, E.V.Korolev, AIP Conference Proceedings, 20-26 (2016)

3. A.S. Inosemtsev, E.V. Korolev, Stroitelnye materialy, 1-2, 38-47 (2016)

4. E.V. Tkach, MATEC Web of Conferences, 86, Moscow (2016)

5. N.Y. Yaskova, D.N. Silka, V.S. Kankhva, I.G. Lukmanova. Finance and credit in construction. College textbook for the students. Moscow (2011)

6. A.D. Ishkov, T.N. Magera. Procedia Engineering, 117, 148-153 (2015) 